\title{
AC 2012-4158: CASE STUDIES IN ENGINEERING ECONOMICS FOR MANUFACTURING COMPETITIVENESS
}

\section{Dr. Priya Manohar, Robert Morris University}

Priyadarshan Manohar is an Associate Professor of engineering at Robert Morris University, Pittsburgh, Penn. He has a Ph.D. in materials engineering (1998) and graduate diploma in computer science (1999) from the University of Wollongong, Australia, and he holds a bachelor's of engineering (metallurgical engineering) degree from Pune University, India (1985). He has worked as a postdoctoral Fellow at Carnegie Mellon University, Pittsburgh (2001-2003), and at BHP Institute for Steel Processing and Products, Australia (1998-2001). Manohar held the position of Chief Materials Scientist at Modern Industries, Pittsburgh (2003-2004) and Assistant Manager (Metallurgy Group), Engineering Research Center, Telco, India (1985-1993). He has published more than 50 papers in peer-reviewed journals and conferences, including a 2007 Best Paper Award by the Manufacturing Division of the American Society for Engineering Education (ASEE), three review papers, and three book chapters. He has participated in numerous national and international conferences. He is a member of ASM International, TMS, ACerS, AIST, ASEE, IMEA, and a registered Chartered Professional Engineer. Manohar's research interests include mathematical and computer modeling of materials behavior, thermomechanical processing of steels and other metallic materials, microstructural characterization, and structure-property relationships. He has conducted a number of technical failure investigations, consulted on various materials-related problems, and acted as an expert witness in a court of law. 


\section{Case Studies in Engineering Economics for Manufacturing Competitiveness}

\section{Background}

The importance of competitiveness in manufacturing industry cannot be overemphasized in the face of rapidly changing globalized economy. Competitiveness may be achieved through various mechanisms such as designing and building distinguished products, offering outstanding service, producing high product quality and of course by developing cost competitiveness ${ }^{1)}$. In this regard, it is recognized that undergraduate education mainly focuses on the technical and design aspects of the engineering profession while many other aspects including marketing, costing, project and financial management, which are the essential needs of the contemporary manufacturing businesses, receive much less attention ${ }^{2}$. While the subject of engineering economy has been incorporated in undergraduate education for a number of years, it realized that the course content and teaching methods have not kept pace with time. For example, a study by Needy et al. , $^{3,}$ conducted as a two-phase survey in 1995 and 1997 of pedagogy of engineering economics found that nearly $47 \%$ of the respondents felt the need to redesign how the subject is taught in the class. Several initiatives suggested by the respondents were:

- Increasing design content

- Expanding cost estimating and accounting

- Incorporating interactive software

- More active learning

- Adding real world projects

Another pedagogical issue suggested is that the curriculum of the course has failed to move forward with the times and has in fact "become stagnant"5). It is suggested that the curriculum being taught now is almost identical to that taught many decades ago. Efforts are being made ${ }^{6-9)}$ to address this issue by introducing computer-based methods, economic simulations and stochastic algorithms in course curricula. However, the main problem lies in the fact that the traditional engineering economy instruction puts more emphasis on routine and trivial calculations and places much less emphasis on the analysis and decision making processes ${ }^{10)}$. Case studies are even rarely used (less than $18 \%$ of the faculty surveyed utilized case studies) in the teaching tool box ${ }^{11,12)}$ even though case studies allow students to gain an insight into the theoretical principles being presented in the class room via their practical applications described in the case studies.

This paper describes the teaching of engineering economy based on several well chosen case studies. It is hypothesized that the students' interest in the subject matter would be increased due to the practical and realistic insights provided by the case studies involving engineering economic applications. The case studies are discussed in the class to highlight the importance of financially responsible decision making through data collection, data analysis and communication. This paper will present some of the case studies selected for this purpose and the students' response to the case study based teaching and learning approach. 


\section{Course Management}

\subsection{Course Description}

This course is designed to expose the students to ideas and techniques in cost estimating and financial analysis that engineers use to evaluate their decisions and designs. Principles of engineering economy (the time value of money, interest rates, cash flow diagrams and economic equivalence) are reviewed and then applied to decisions typically faced by practicing engineers. Financial analysis is applied across the entire engineering decision-making process including problem definition, alternative solution generation, cost estimation and timing, and selection under assumptions of certainty, risk and uncertainty. The course was initially delivered at a graduate level. The class consisted not only of students who were working professional engineers with several years of experience, and but it also had several integrated BS/MS students who did not have significant work experience other than their summer work and internships. The recommended textbook for the course was the ever-popular Engineering Economic Analysis by Newnan et al. (11 ${ }^{\text {th }}$ Edition, Oxford University Press, 2012).

\subsection{Course Map}

The students are introduced to various ideas in engineering economy with the help of theory, inclass exercises including group discussion and problem solving and more detailed case studies as home work problems. The topics covered in the class are as follows:

- Role and Purpose of Engineering Economic Analysis

- Decision Making under Risk and Uncertainty

- Ethics in Economy

- Cost Concepts (e.g. different types of costs such as capital investment, labor, material, maintenance, property taxes, insurance, operations, quality, disposal, and overhead; life cycle costing); Cost Estimation (parametric, indexing, segmenting, power sizing, triangulation, learning curves, industry and company data analysis); and Activity Based Costing

- Review of Time Value of Money, Simple and Compound Interest, Cash Flow Diagrams, Analysis and Equivalence

- Present Worth (PW), Annual Worth (AW), Future Worth (FW), Internal Rate of Return (IRR), Minimum Attractive Rate of Return (MARR), External Rate of Return (ERR), Rate of Return (RoR) Analysis

- Spreadsheet Modeling

- Analytical Techniques: Incremental, Benefit : Cost Ratio, Break-Even, Payback Period, Replacement, Sensitivity

- Depreciation

- Individual and Corporation Income Taxes

- Minimum Cost of an Asset

- Public Projects, Investment, and Decision making

- Inflation and Global Economies

- Accounting Reports (Balance Sheet, Income Statement, Cash Flow) 


\subsection{Student Assessment}

Student assessment was based on the following tasks:

- $\quad$ Seven assignments at 100 points each $=700$ points $(58 \%)$

- Seven case studies at 50 points each $=350$ points $(29 \%)$

- Final comprehensive exam $=150$ points $(13 \%)$

for a total of 1200 points $(100 \%)$ assessment.

\section{Course Delivery}

The course delivery consisted of various pedagogical tools including formal lectures, a set of case studies followed by guided group discussion, and traditional pen and paper exams. The case studies were selected from the book Cases in Engineering Economy $2^{\text {nd }}$ ed., by William Peterson and Ted Eschenbach, Oxford University Press, 2009, after determining their appropriateness in the context of course curriculum. Discussion questions and case study analysis was prepared in advance. Brief descriptions of the chosen case studies are given below:

\subsection{Selected Case Studies}

A case study was assigned each week that dealt with different aspects of engineering economic analysis. The students were expected to determine economic facts from the given conversations and statements and figure out a solution to the problems posed in the case study. They were required to analyze data using spread sheets in many cases and apply the knowledge learnt in the class to arrive at defensible solutions. Discussion questions were developed for each of these cases and a certain amount of class time was set aside for guided discussion sessions to elaborate on the key ideas. Some of the selected cases had the following themes:

- A hybrid vehicle: Given that 52 different models of hybrid vehicles will be available by 2012 (which is currently about $4.2 \%$ U.S. market), and the market share of the hybrid vehicles is expected to rise to $7 \%$ by 2015 , what economic and non-economic factors the customers may be concerned about regarding the conversion to alternative fuel vehicles?

- The can cruncher: A local manufacturer would like to develop his own product, a can cruncher equipment, for wholesale or retail sale rather than simply fabricating components to be incorporated into the products of others. Given the details of the design, estimate a cost based on estimated development time and market size and determine break-even production quantity.

- A free lunch?: "We will install new HVAC equipment for you, absolutely free!! Just sign a three-year contract to split 50/50 any savings the equipment generates on the use of equipment plus pay for a service contract for the equipment's maintenance. We will take out the loan for the equipment and installation and pay off the loan with our share of the savings. After three years, the equipment is yours! You'll only be giving us some of the money you are paying to the power company for electricity. The service contract for the equipment is $\$ 15,000$ per year, but think of your peace of mind!" Evaluate if this is a free lunch or if there is a catch somewhere based on other financial data available. What data would you need? What evaluation criteria would you choose?

- The Cutting Edge: Evaluate a request for proposal, which, if successful, would exceed manufacturing capacity of a manufacturer. Evaluate options for expansion - add 
manufacturing capability by adding machines (which machine? - analyze economics of manufacturing for four machine types here) or outsource manufacturing locally or overseas.

- Molehill and Mountain Movers (MMM): MMM runs a fleet of heavy construction equipment and sells gravel for roadwork from its pit. They are opening a new section of the pit, and they must choose between conveyor and front-end loader systems for loading the trucks. In the past, they have used front-end loaders. Analyze these two options for machinery based on first costs, maintenance costs and salvage values, given depreciation. Include sensitivity analysis for different estimated cost parameters and the effects of inflation over a 10 year horizon.

- Mr. Speedy: Mr. Speedy is a heating and air conditioning repair business that was established 23 years ago. Today the business revolves around 20 vans that are on the streets, and another four for backup in the shop. The 20 vans are not all out at once as there is day, night, and weekend coverage using 32 technicians. Each technician is assigned to a van, and each van has only one or two technicians assigned to it. Determine least cost operations and replacement schedule for Mr. Speedy including depreciation.

- The Great White Hall: Flatland Views city council has advertised for proposals to build a new community center, a library and a theatre but the city council cannot agree on how to evaluate the submitted proposals. The request for proposal (RFP) specified that respondents had to meet certain basic needs, although optional items could be included. The RFP also asked that each respondent calculate a benefit/cost $(\mathrm{B} / \mathrm{C})$ ratio using a discount rate of $12 \%$. What are the options for analyzing and making decisions on this public funding proposal? What are the opportunities for negotiation? How do you arrive at the best combination from submitted proposals?

\subsection{Case Analysis}

The students were provided with discussion question and hints for analysis. Each case was initially discussed in the class to facilitate the identification of the data given, the parameters to be determined and if there were any missing data. If such was the case, then they were asked to make suitable assumptions based on the current market conditions. For example, the following information was provided for the MMM case given above:

\section{Discussion Questions:}

1. Compare the equivalent uniform annual costs (EUAC) for the conveyor and the front loader assuming that inflation is $0 \%$ under four depreciation methods: (1) straight line, (2) SOYD, (3) double declining balance, and (4) MACRS. Do the different depreciation methods have similar impacts on the conveyor and the loader?

2. Assuming that inflation is $10 \%$, use the same four depreciation methods and redo option 1 .

3. Graph the EUACs for each depreciation method as a function of the inflation rate, between $0 \%$ and $15 \%$.

4. Compare the relative sensitivity of the inflation rate, the annual operation cost, the tax rate, variations in the first cost or salvage, and the choice of depreciation method. 


\section{Suggestions for Additional Analysis:}

1. Assume that MMM is profitable so that costs and depreciation are deductible from taxable income.

2. The Excel function that can calculate MACRS depreciation is VDB. This allows declining balance with a switch to straight-line and no salvage value. For the time period arguments see your text. (Excel's DB function makes different assumptions.)

The students discussed the case again after the cases were graded by the instructor and returned to them. The students found case studies to be extremely helpful in understanding how to apply the theory to practical situations to reach an optimal solution in an objective manner.

\section{Applicable ABET Outcomes}

Criterion 3 ABET outcomes applicable for this course are suggested as follows:

Engineering graduates have:

(2): an ability to apply knowledge of mathematics, science and engineering

(3): an ability to design a system, component or process to meet desired needs

(7): an ability to communicate effectively

(8): had the broad education necessary to understand the impact of engineering solutions in a global societal context

(10): a knowledge of contemporary issues

(11): an ability to use the techniques, skills, and modern engineering tools necessary for engineering practice

Manufacturing Engineering track-specific ABET outcome applicable for this course is suggested to be:

(M3): graduates appreciate the necessity for manufacturing competitiveness and understand how to create competitive advantage through manufacturing planning, strategy and control

The outcomes may be assessed via homework assignments, term project and exams. It is expected that the applicable outcomes list would be revised based on the outcomes assessment.

\section{Course Assessment}

\subsection{Student Performance}

The student performances in the courses with traditional instruction without case studies in Spring 2009 and Spring 2011 terms are shown in Figure 1. 


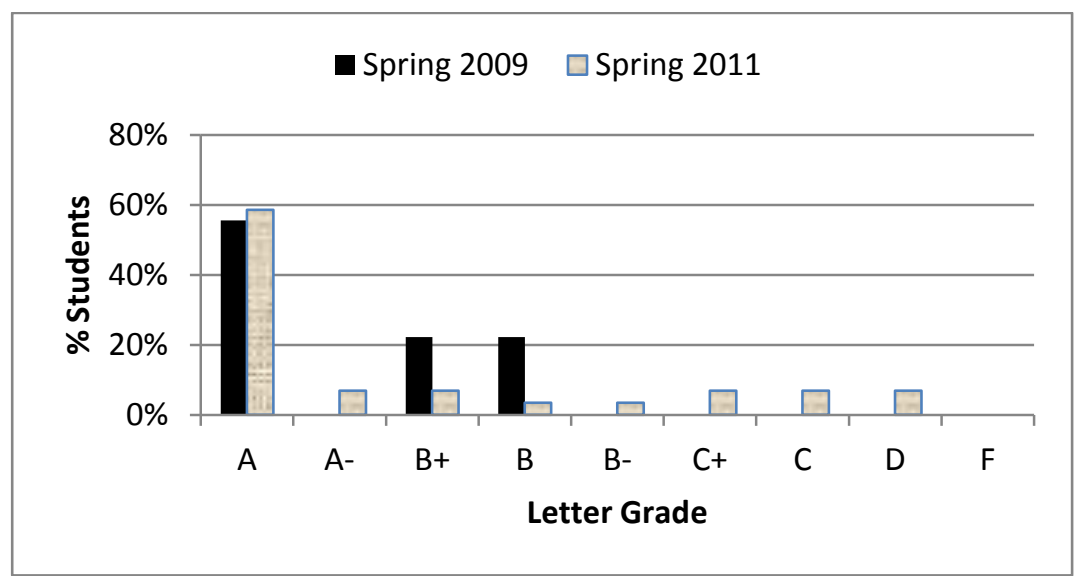

Figure 1: Student final grade distribution for Spring 2009 and Spring 2011 terms.

It is evident from Figure 1 that the students performed well in both terms.

\subsection{Student Satisfaction}

The traditional course delivery without the incorporation of case studies established a baseline for student satisfaction. A third party survey tool - Student Instructional Report II (SIR II) was employed. The data from these surveys over couple of years are presented in the Table 1 as follows.

Table 1. SIR II Data for Spring 2009 and Spring 2011 terms.

\begin{tabular}{|l|c|c|}
\hline \multicolumn{1}{|c|}{ Assessment Parameter } & Spring 2009 & Spring 2011 \\
\hline $\begin{array}{l}\text { \# of Students Surveyed / Out } \\
\text { of Total \# Enrolled }\end{array}$ & 16 & $24 / 29$ \\
\hline $\begin{array}{l}\text { Course Organization and } \\
\text { Planning }\end{array}$ & 3.89 & 4.18 \\
\hline Communication & 3.74 & 3.92 \\
\hline Faculty/Student Interaction & 3.91 & 3.93 \\
\hline $\begin{array}{l}\text { Assignments, Exams and } \\
\text { Grading }\end{array}$ & 3.75 & 3.48 \\
\hline Course Outcomes & 3.18 & 3.53 \\
\hline $\begin{array}{l}\text { Student Effort and } \\
\text { Involvement }\end{array}$ & 3.56 & 3.58 \\
\hline Overall Quality of Instruction & 3.63 & \\
\hline
\end{tabular}


The course assessment for the case-study based course in Spring 2011 was done through student feedback and through SIR - II survey tool. Some of the comments on different aspects of the course based on student feedback are given below:

$>$ Thank you for a challenging and exciting learning experience. We found that the interpretation of the conversations given in the case study to be difficult and we had tough time extracting data from them.

$>$ I really believe the topics I learned in this class will be valuable to me for the rest of my life.

I enjoyed your class very much.

SIR II instructional survey data for this course is now available as shown in Table 2 below.

Table 2. SIR II Data for Fall 2011 term.

\begin{tabular}{|l|c|}
\hline \multicolumn{1}{|c|}{ Assessment Parameter } & Fall 2011 \\
\hline \# of Students Surveyed & 4 \\
\hline Course Organization and Planning & 4.60 \\
\hline Communication & 4.56 \\
\hline Faculty/Student Interaction & 4.47 \\
\hline Assignments, Exams and Grading & 4.12 \\
\hline Course Outcomes & 4.27 \\
\hline Student Effort and Involvement & 4.60 \\
\hline Overall Quality of Instruction & \\
\hline
\end{tabular}

The data given in Tables 1 and 2 demonstrate clearly that case study-based instruction was a lot more effective in all aspects of educational survey and students were much more satisfied with this method than the traditional instructional methods. Case study based method strongly encouraged peer interaction as well as faculty-student interaction and this appears to be a major advantage of this instructional strategy. Also, case studies related well to the working students and therefore they seemed to enjoy working on those problems and did not mind the extra workload the case studies placed on them. However, it should be noted that the class size was small in this instance which perhaps facilitated effective faculty-student interaction. It would be interesting to see if this instructional quality will be upheld in a larger class size environment. 


\section{Summary}

Traditional teaching tools for engineering economy have served the students well over the years. However, there is a need to enhance the learning experience based on contemporary students' expectations. It is shown that the case study based teaching approach utilized here incorporates active learning and the chosen case studies highlight the applications of theoretical principles to real-world business problems. Case study-based analysis also enhances communication skills of the students. The students found the new case-study based teaching approach challenging as well as rewarding.

\section{References}

1. Grose, T. K., "Making It: Revolutionary Manufacturing Processes Stir Hope of a U. S. Industrial Revival”, ASEE Prism, Nov. 2011, pp. 28 - 33

2. Wells, D., "A Framework for Student Learning in Manufacturing Engineering", American Society for Engineering Education Annual Conference Proceedings, 2006.

3. Needy, K. L., Lavelle, J. P., Nachtmann, H., and Eschenbach, T. G., "An Empirical Analysis of Engineering Economy Pedagogy," The Engineering Economist, Vol. 45, No. 1 (2000), pp. 74 - 92.

4. Nachtmann, H., Needy, K., Lavelle, J., and Eschenbach, T., "Investigating Engineering Economy Pedagogy", American Society for Engineering Education Annual Conference Proceedings, 2007.

5. Hartman, J. C., "Suggestions For Teaching Engineering Economy at the Undergraduate Level," The Engineering Economist, Vol. 44, No. 1, 1999, pp. 110-125.

6. Hartman, J. C., "Engineering Economy: Suggestions to Update a Stagnant Course Curriculum”, American Society for Engineering Education Annual Conference Proceedings, 1998.

7. Bafna, K. and Aller, B., "Enhancing the Learning of Engineering Economy with Innovative Technology and Teaching," American Society for Engineering Education Annual Conference Proceedings, 2007.

8. Coates, E. R., Vajpayee, S. K., and Juneau, J., "Introducing Engineering Economy Students to Real Options", American Society for Engineering Education Annual Conference Proceedings, 2003.

9. Evans, E., Nachtmann, H., and Needy K., "A Look into Engineering Economy Education Literature”, American Society for Engineering Education Annual Conference Proceedings, 2010.

10. Elizandro, D. W. and Matson, J. O., "Taking a Moment to Teach Engineering Economics Education," The Engineering Economist, Vol. 52, No. 2, 2007, pp. 97-116.

11. Lavelle, J. P., "Engineering Economy: A Survey of Current Teaching Practices", American Society for Engineering Education Annual Conference Proceedings, 1996.

12. Lavelle, J. P., Needy, K., and Nachtmann, H., "Engineering Economy: A Follow Up Analysis of Current Teaching Practices", American Society for Engineering Education Annual Conference Proceedings, 1997. 